\title{
Development of a sensitive and specific qPCR method to detect duck and goose DNA in meat and feathers
}

\author{
Małgorzata Natonek-Wiśniewska ${ }^{1} \cdot$ Piotr Krzyścin ${ }^{1} \cdot$ Monika Bugno-Poniewierska ${ }^{1}$
}

Received: 23 April 2018 / Accepted: 8 September 2018 / Published online: 5 October 2018

(c) The Author(s) 2018

\begin{abstract}
This study developed a method to identify the species of duck and goose DNA extracted from various matrices. The research material included meat, down, whole feathers, and blood. The analysis was performed with real-time PCR using minor groove binder probes and primers that bind to cytochrome $\mathrm{b}$ (duck) and $12 \mathrm{~S}$ ribosomal RNA (goose) sequences. For all matrices, the reactions were species-specific. Cross-reactions either did not occur or occurred after 36 cycles, corresponding to an amplification for the species content of $10^{-5} \%$, i.e., several times below the limit of detection $(\mathrm{LOD}=0.01 \%)$ and limit of quantification ( $\mathrm{LOQ}=0.1 \%$ ). The standard curves obtained by consecutive dilutions were linear $\left(R^{2}>0.99\right)$, the slopes ranged from 3.2 to -3.6 , and the retardation factors were 23-26. The amplitude threshold analysis demonstrated that significant differences between successive matrices make it impossible to select one reference material to produce a standard curve effective for analyzing each type of matrix. A comparison between the reference material and the test material reveals that the accuracy of the developed method (the match between the actual and the measured value) is above $78 \%$. Validation methods indicate that this method can be used to identify duck and goose DNA in the analyzed matrices.
\end{abstract}

Keywords Species identification $\cdot$ Down $\cdot$ Meat $\cdot$ Ducks $\cdot$ Geese $\cdot$ MGB probe $\cdot$ MtDNA

\section{Introduction}

The species identification of ducks and geese has a number of important applications, including the testing of meat products [1-3], which are often adulterated with cheaper substitutes from other species due to cost; the testing of feathers and down during quality and quantity control of bedding inserts or outer garments; and the identification of birds involved in criminal cases or accidents $[4,5]$. Species identification can be a challenge when only partial, processed, or damaged fragments of meat or feathers are available. In such cases, morphological identification can be difficult or even impossible, and the only possible tests may be DNA based. Species identification based on DNA often involves conventional polymerase chain reaction (PCR) and electrophoresis $[1,6]$, Sanger's sequencing $[6,12]$, and real-time PCR [2, $3]$. The last of these methods allows for quantitative species

Małgorzata Natonek-Wiśniewska

malgorzata.natonek@izoo.krakow.pl

1 Department of Animal Molecular Biology, National Research Institute of Animal Production, ul. Krakowska 1, 32-083 Balice, Poland detection, which provides an advantage for commercial quality control of products derived from bird species.

For species identification, the proposed method must enable DNA isolation and provide repeatable species-specific results. While DNA isolation from meat or meat preparations is generally not problematic [7], obtaining quality genetic material from down is more challenging. Most of the latest feather DNA extraction techniques are based on genetic material sourced from the calamus $[8,12]$. There are also reports of extraction from other parts of the feather [9], even from a single barb [6].

Amplification of species-specific gene fragments should take place independent of the template type; consequently, growth of the reaction product may vary. The efficiency and DNA amplification rate for individual templates must be analyzed to develop a method for quantitative determination of a species composition present in a variety of materials. This issue takes on additional significance, because there is no official or standard reference material for the quantitative determination of duck and goose DNA that would enable identification to be based on the same reference material worldwide. 
Minor groove binder (MGB) probes were chosen for the study because they are more specific than others. For the identification of duck DNA, the method involving this type of probe and described in the literature, was based on a genome fragment within cytochrome b [10]. For the identification of goose DNA, no information was found in the literature concerning the application of MGB probes. Such a probe was designed for a selected $12 \mathrm{~S}$ ribosomal RNA fragment that had been identified using BBQ probe [2]. This study compared the amplification efficiencies of selected fragments of species-specific genes in various templates used commercially and derived from ducks and geese. Based on this information, a method for quantitative species identification was developed.

\section{Materials and methods}

\section{Samples and sample preparation}

This study involved the meat, blood, and feathers (down and calamus) of ducks (Polish Pekin P-33, English Pekin LSA, French Pekin P-9, Danish Pekin P-8, KhO-1, D11, and Runner) and geese (White Kołuda, Roman, Slovakian, W11, and W33). In addition, the study used food products (meat, pâté, stuffing) containing a duck or goose component as well as feathers of budgerigar, cockatiel, hoopoe, canary and pigeon. The food products were purchased in a health food store. All the other samples were owned by the National Research Institute of Animal Production. Meat and blood samples were frozen at $-20{ }^{\circ} \mathrm{C}$, and feathers were stored at room temperature.

A representative sample was prepared from each test material, and three laboratory samples for each test material were selected: meat $(100 \mathrm{mg})$, blood $(20 \mu \mathrm{l})$, and down or feathers (10-13 mg). Total DNA was isolated from the meat using the AX Food kit (A\&A Biotechnology), and DNA from the blood and feathers was isolated using the Sherlock AX kit (A\&A Biotechnology) according to the manufacturer's instructions. Feathers were vigorously stirred on a vortex mixer during incubation with proteinase $\mathrm{K}$. The DNA concentration of the obtained extracts was measured with a NanoDrop spectrophotometer (Thermo Fisher), while the purity of the extracted DNA was determined through the absorbance ratios at $260 \mathrm{~nm}$ and $280 \mathrm{~nm}$.

\section{Determination of species-specific DNA}

Goose and duck DNA was determined by Real-Time PCR using the StepOne Plus Thermal Cycler Software v2.3 (Applied Biosystems). This process used primers complementary to a fragment coding for cytochrome $\mathrm{b}$ in ducks and for $12 S$ rRNA in geese, as well TaqMan ${ }^{\circledR}$ minor groove binder probes (Thermo Fisher) $[2,10]$. Our own probe of 5'-ATA GGG CAC ACG GAA A-3' was used instead of the probe proposed by Pegels et al. To determine the method parameters, the specificity, linearity, and accuracy, as well as the limit of quantitation (LOQ), and the limit of detection (LOD) were checked. To this end, reactions were performed with DNA originating from a mixture of duck and goose matrices (meat, blood and feathers separately) at a ratio of $0.01 \%, 0.1 \%, 1 \%, 10 \%, 30 \%, 50 \%, 70 \%$ and $100 \%$ for each species. The molecular specificity of the methods was determined through in silico analysis of primers with DNA from several species of farm animals (cow, pig, horse, and sheep), companion animals (dog and cat), wild animals (red deer, roe deer, and fallow deer) and fowl (hen, turkey, guinea fowl, canary, pigeon, and swan), followed by crossreactions with DNA from hens, turkeys, ducks, and geese. Species-specific reactions were performed for each template. The quantitative determination was performed by reference to the standard curves of five dilutions (factor $=10$ ). DNA was obtained from a mixture of single-species templates of the identified species. For curve analysis, parameters such as retardation, slope, and linearity were determined. The LOD was determined in a species-specific reaction for DNA dilutions corresponding to the content of the identified species at the levels of $1 \%, 0.1 \%$, and $0.01 \%$.

\section{Calculations and statistical analysis}

Analysis of the amplification threshold $\left(C_{\mathrm{T}}\right)$ was performed for all templates. To compare the obtained values, significant differences between them were determined using oneway analysis of variance (Excel) with a significance level of $\alpha=0.05$. Differences in the $C_{\mathrm{T}}$ values as well as the standard deviations within breeds and between breeds were calculated. For selected samples, the DNA concentrations were determined based on a standard curve. These values were determined using the qPCR monitoring software integral to the thermal cycler. The $C$ T results were presented as a mean of three measurements for each sample and the standard deviation between them. For these samples, the relative accuracy $(D)$ was also determined as a percentage of the measured value in the actual value, using the formula $D \%$ $=\left(c_{\text {measured }} / c_{\text {actual }}\right) \times 100 \%$, (where $\mathrm{c}$ is the concentration of DNA of a given species in the template).

\section{The use of the developed methods to identify products of avian origin}

The elaborated methods were used to analyze commercial food products, the feathers of birds living in our climate zone, and exotic birds whose birds can be traded. The amount of DNA from the determined species in food products was established based on a standard curve 
produced from DNA extracted from raw duck or goose meat. For the analysis of down, a standard curve generated from feathers of the representatives of the determined species was used. The results, in the form of DNA concentration of the determined species, were presented as a mean from three independent isolations of DNA obtained from the same sample. Relative accuracy was also determined $(D \%)$.

\section{Results}

\section{DNA isolation}

The DNA extraction parameters show that DNA was properly isolated from the specific templates for meat using the AX Food kit (A\&A Biotechnology) and for blood and feathers using the Sherlock kit (A\&A Biotechnology). The DNA concentration and quality ranged from 350 to $550 \mathrm{ng} / \mu \mathrm{l}\left(A_{260 / 280}=1.88-1.98\right)$ for meat and from 50 to $150 \mathrm{ng} / \mu \mathrm{l}\left(A_{260 / 280}=1.88-1.95\right)$ for blood. The DNA concentration obtained from feathers was in the range of 50-470, and the concentration obtained from calamus and down was 33-135 ng/ $\mu 1$. In both cases, purity expressed as the $A_{260 / 280}$ parameter ranged from 1.64 to 1.99 .

\section{Qualitative and quantitative analysis: specificity and sensitivity of the primers and probes}

The $C_{\mathrm{T}}$ values demonstrate that the presented primers and probes are species-specific (Table 1). Positive reactions were only obtained for DNA of the determined species; cross-reactions occurred sporadically and not until after 36 cycles. Standard curves were generated for successive templates (as in Table 1 for down, meat, and blood) and calculated with the equation $C \mathrm{~T}=f(\log c)$. The curves were linear at template concentrations of $0.1-100 \%$, their slope coefficients ranged from -3.188 to -3.634 , and the retardation factors were in the $23.85-26.87$ range. The best curve parameters were obtained for meat; for this template, the efficiency $\left(\mathrm{Eff}=10^{-1 / \text { slope }}-1\right)$ is closest to $100 \%$. The $C_{\mathrm{T}}$ values for the samples at the $0.01 \%$ concentration were below 36 , but because the values departed from linearity, the limit of detection (LOD) was assumed for this concentration, whereas the limit of quantification (LOQ) was set as $0.1 \%$ because this was the lowest value within the linear range of function.

One-way analysis of variance for the templates (meat, blood, and down) from the geese and the ducks showed statistically significant differences between the $C_{\mathrm{T}}$ values for individual templates (Table 2). For this reason, feathers were further analyzed using curves generated from templates of the same type.
Table 1 Species-specific reactions and cross-reactions

\begin{tabular}{|c|c|c|c|}
\hline \multicolumn{2}{|l|}{ Target: geese } & \multicolumn{2}{|l|}{ Target: ducks } \\
\hline Template & $C_{\mathrm{T}}$ mean & Template & $C_{\mathrm{T}}$ mean \\
\hline White goose-down & 20.20 & Pekin duck_-blood & 19.05 \\
\hline White goose-meat & 16.09 & Pekin duck-meat & 18.94 \\
\hline White goose-blood & 17.83 & Pekin duck-down & 22.68 \\
\hline Turkey—meat & Undetermined/40.22 & White goose-blood & Undetermined \\
\hline Pekin duck—down & 36.35 & Turkey-meat & Undetermined \\
\hline Pekin duck-meat & Undetermined/37.85 & Turkey_blood & Undetermined \\
\hline Pekin duck—blood & 37.62 & Hen-meat & Undetermined \\
\hline Hen-meat & Undetermined/40.37 & Hen-blood & Undetermined \\
\hline
\end{tabular}

Table 2 One-way analysis of variance

\begin{tabular}{llllll}
\hline Template & $\begin{array}{l}\text { No. of analyzed } \\
\text { animals }\end{array}$ & $F$ & $p$ & Test $F$ & Interpretation \\
\hline White goose-down & 3 & 5.18 & 0.041 & 4.74 & $*$ \\
White goose-meat & 4 & & & & \\
White goose-blood & 3 & & & & \\
White duck-down & 3 & 544.52 & $1.44 \mathrm{e}-{ }^{4}$ & 9.55 & $*$ \\
White duck-meat & 4 & & & & \\
White duck-blood & 3 & & & & \\
\hline
\end{tabular}

*Significant difference 


\section{Analysis of goose feathers}

The goose feather results are presented as the mean of the $C_{\text {T }}$ values from three independent sample isolations. The $C_{\text {T }}$ results demonstrate a higher repeatability of the results for the samples obtained from the calamus. Within-breed $C_{\mathrm{T}}$ differences were small (less than one cycle), whereas the analogous differences for down were greater (around two cycles). A similar pattern occurred for the $C_{\mathrm{T}}$ standard deviation (Table 3). Differences within all breeds resulted in even higher $C_{\mathrm{T}}$ values of 1.48 and 7.26 for feathers and down, respectively. For both templates, one-way analysis of variance showed that there were statistically significant differences in the amplification time for individual samples within breeds and within templates $(p<0.05 \%$, $F_{\text {empirical }}>F_{\text {tabl }}$, where $F$ means F-Snedecor); within the same template, the analysis showed no statistically significant differences between the breeds. For this reason, the quantitative determinations made use of the standard curve from a mixture of DNA from animals of a single breed, namely line W33 for calamus and line W11 for down. The accuracy of both templates was $66-108 \%$ for calamus and 47-199\% for down (Table 3). The smallest differences between measured and actual values were for samples whose species were consistent with the standard.

\section{Analysis of duck feathers}

Like the goose feather analysis, repeatability of the duck feather results was higher for samples obtained from calamus than for those obtained from down. Within-breed differences for calamus $\mathrm{C}_{\mathrm{T}}$ values were small (less than one cycle), while for samples obtained from down, the corresponding differences were higher (around three cycles). A similar pattern occurred for the standard deviation between these values (Table 4). Between-breed differences were also small for feathers (less than two cycles) and three times higher for down. One-way analysis of variance showed that within-breed differences between individuals were statistically significant $\left(p<0.05 \%, F_{\text {empirical }}>F_{\text {tabl }}\right)$. For samples obtained from calamus, the analysis showed no differences for individual breeds; for samples obtained from down, the amplification time was correlated to the breed $(p=0.05 \%)$. Therefore, the quantitative interpretation of duck feathers (calamus) used a standard curve generated from a mixture of DNA from one breed (K2), while the quantitative determination of down used a curve generated from a mixture of DNA from all analyzed samples. The accuracy for both templates was $107-124 \%$ for calamus and $38-208 \%$ for down (Table 4 ).

\section{Analysis of products of bird origin}

The results were presented as a mean value of DNA concentration from the determined species from three independent isolations of a sample (quantity mean). The determined accuracy was $98-136 \%$ (Table 5). Cross-analysis with DNA obtained from the feathers of other bird species, did not yield a reaction product or the reaction was too late and assumed the value of zero (Table 6).

\section{Discussion}

These results demonstrate that the developed tests are highly suitable for the qualitative and quantitative determination of duck and goose DNA in meat, blood, and feathers. The quantity and quality of DNA isolation is dependent on the template. Quality extracts are easily obtained from the meat and blood templates. For feathers, the isolation efficiency depends on the tested fragment, and the isolation efficiency is ten times lower for down than for calamus. These results are in accordance with earlier observations [11]. The slightly decreased purity parameter $(<1.8)$ for feather samples is indicative of protein contamination, likely associated with keratin, which other authors have reported in feather extracts [12].

The proposed primers are species-specific and produce amplicons of short length. This method is highly sensitive and enables qualitative identification at $0.01 \%$, which corresponds to $0.015 \mathrm{ng} \mathrm{DNA} /$ reaction and $15 \mathrm{e}^{-4} \mathrm{mg}$ feathers. Quantitative determination is possible from $0.1 \%(0.15 \mathrm{ng}$, $15^{\mathrm{e}-3} \mathrm{mg}$ feathers). By way of comparison, Boonseub et al. [6] reported that species identification was possible based on a single barb. The results for the duck component identification provided a similar sensitivity level to the findings of Hird et al. [10], who used different templates. The statistical analysis reveals the need to adjust the standard curves to the subject template. When a standard curve was created from a mixture of DNA from several individuals of the same species, better fitting with the analyzed samples was obtained, but the accuracy of the test was inadequate, particularly for samples obtained from down. The most accurate measurements will be achieved using a curve consistent with the breed of the analyzed samples, or if such knowledge is not available, by creating a curve from a mixture of DNA derived from samples with maximally different $C_{\mathrm{T}}$ values. Only curves generated in this manner may guarantee an acceptable accuracy of the quantitative determinations.

The method presented above could be applied in the commercial analysis of food or clothing products. It could also be used to resolve litigation disputes where critical evidence takes the form of bird meat or feathers. In addition, an effective method of isolating DNA from feathers can enable 


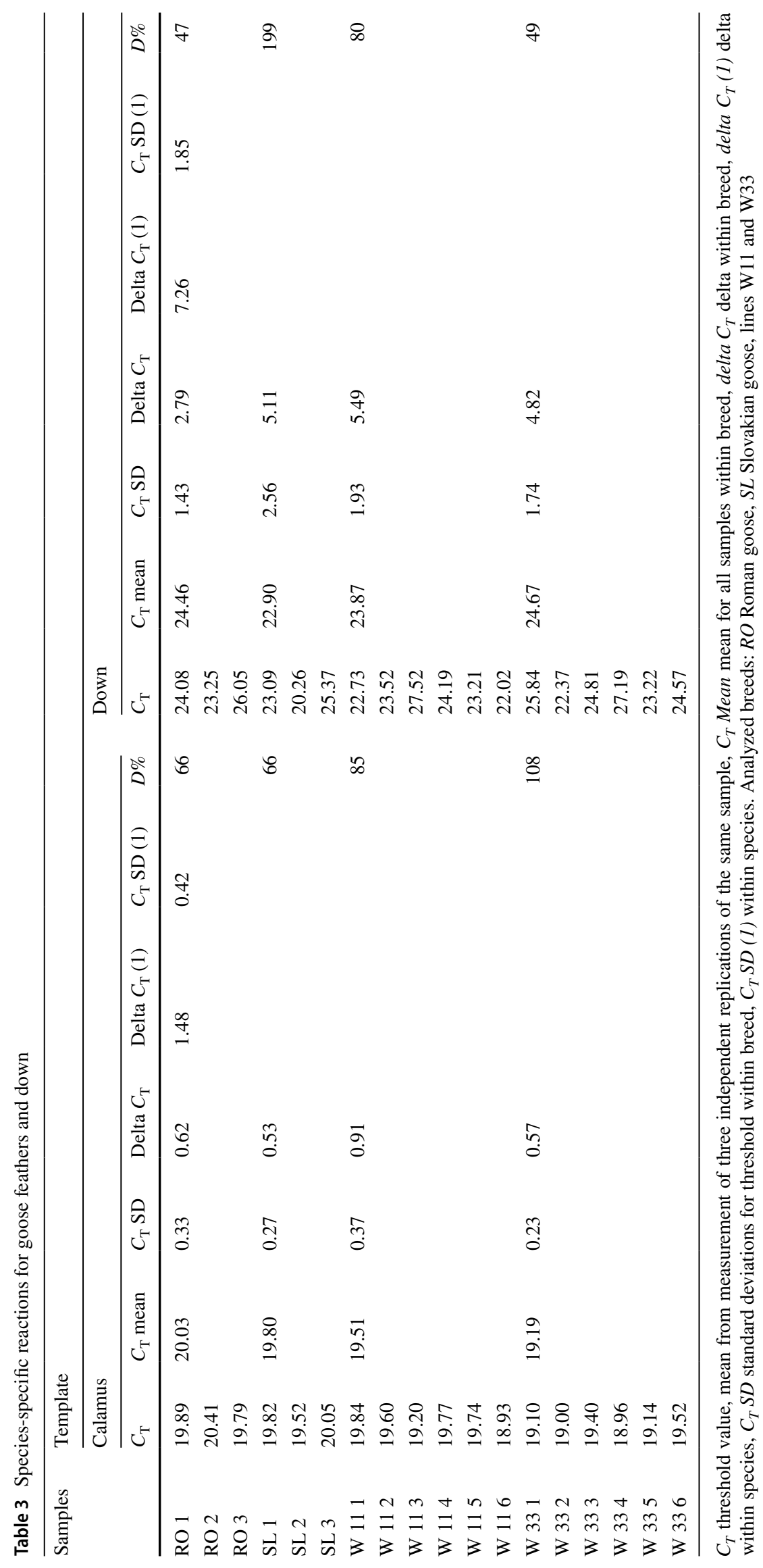




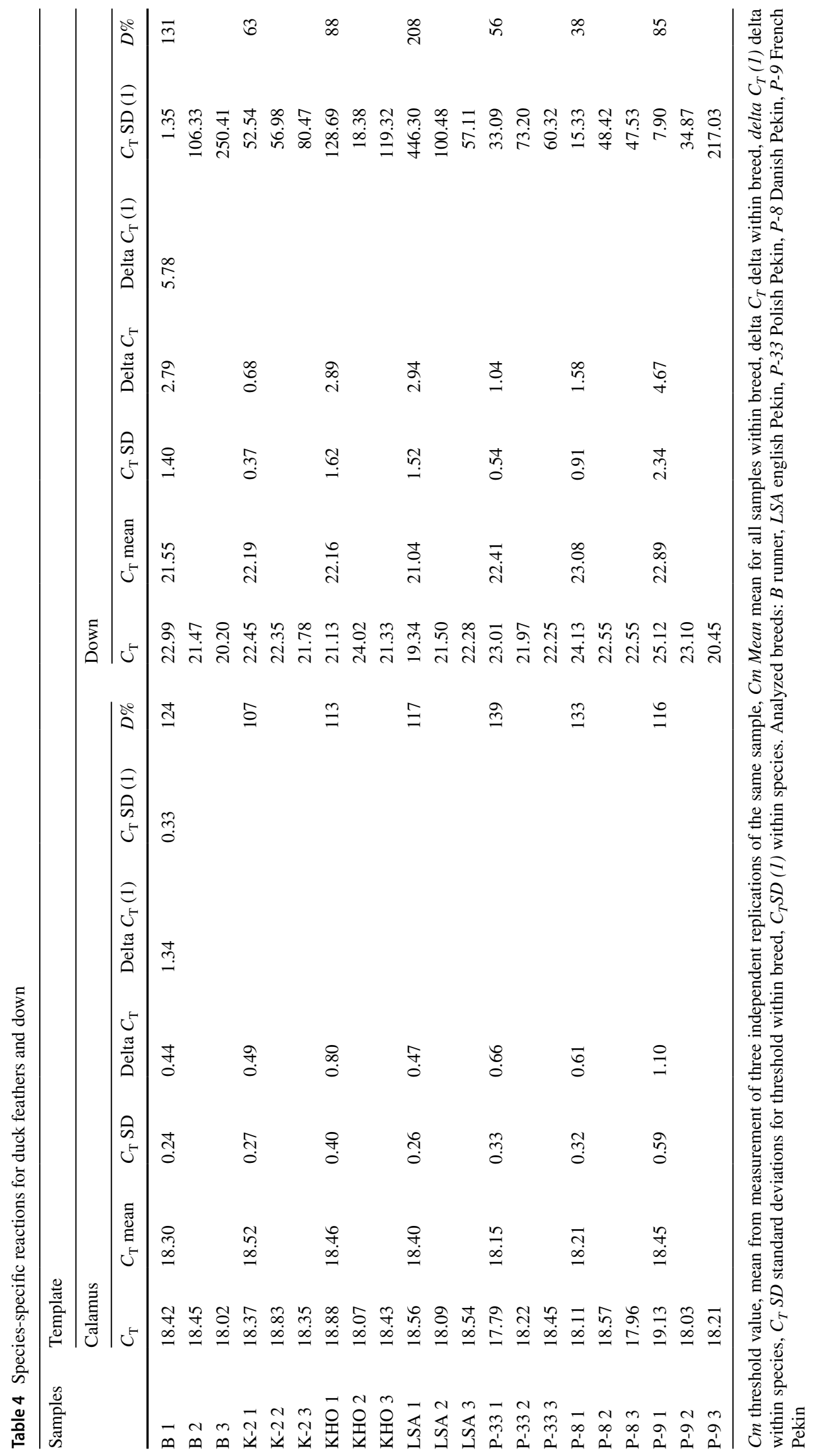


Table 5 Determination of species composition of food products

\begin{tabular}{|c|c|c|c|c|c|c|c|c|}
\hline \multirow[t]{3}{*}{ Sample names } & \multicolumn{7}{|c|}{ Species composition } & \multirow[t]{3}{*}{$D \%$} \\
\hline & \multicolumn{5}{|l|}{ Declared } & \multirow[t]{2}{*}{ Geese $(\%)$} & \multirow{2}{*}{$\begin{array}{l}\text { Quantity mean } \\
\text { Ducks (\%) }\end{array}$} & \\
\hline & Geese $(\%)$ & Ducks (\%) & Turkeys $(\%)$ & Cattle (\%) & Sheep $(\%)$ & & & \\
\hline Pâté & 60 & - & - & - & - & 58.37 & - & 97.28 \\
\hline Pâté & 40 & - & - & - & - & 35.91 & - & 89.78 \\
\hline Pâté & 3 & - & - & - & - & 3.18 & - & 106.00 \\
\hline Stuffing & 0 & 100 & - & - & - & - & 106.97 & 106.67 \\
\hline Stuffing & - & 80 & 20 & - & - & - & 67.58 & 84.48 \\
\hline Raw meat & - & - & 100 & - & - & - & - & - \\
\hline Raw meat & - & - & - & 0.50 & 99.50 & - & 0.00 & - \\
\hline Raw meat & 0.50 & - & - & 99.50 & - & 0.68 & - & 136.00 \\
\hline Raw meat & - & 0.50 & - & 99.50 & - & - & 0.49 & 98.00 \\
\hline
\end{tabular}

$D \%$ accuracy

Table 6 Species analysis of feathers from exotic birds and those typical of our climate zone

\begin{tabular}{lll}
\hline Sample name & Quantity mean \\
\cline { 2 - 3 } & Geese (\%) & Ducks (\%) \\
\hline Budgerigar 1 & 0.00 & 0.00 \\
Budgerigar 2 & 0.00 & 0.00 \\
Cockatiel 1 & 0.00 & 0.00 \\
Cockatiel 2 & 0.00 & 0.00 \\
Pigeon & 0.00 & 0.00 \\
Canary & 0.00 & 0.00 \\
Hoopoe & 0.00 & 0.00 \\
\hline
\end{tabular}

species determination where morphological assessment is not possible due to damage or extremely small samples [4]. This method may contribute to species identification in products containing derivatives from legally protected birds.

\section{Conclusions}

The amplification of selected genes that determine species specificity for meat, blood, feathers, and down was effective for all the evaluated templates.

Species identification from all feather forms was possible from isolations as low as $15 \mathrm{e}^{-3} \mathrm{mg}$.

For each template type, the amplification occurred in a different reaction cycle, so a separate standard curve should be generated for each template.

In practical application, the most accurate measurements will be obtained using a curve that is derived from the same breed as that of the analyzed sample or using a curve that is derived from samples with extremely different $C_{\mathrm{T}}$ values.
Preferably, the curve should be created from the DNA of several animals.

The method can be used for analysis of food products.

\section{Compliance with ethical standards}

Conflict of interest All authors declare that they have no conflict of interest.

Compliance with ethics requirements This article does not contain any studies with human or animal subjects.

Open Access This article is distributed under the terms of the Creative Commons Attribution 4.0 International License (http://creativeco mmons.org/licenses/by/4.0/), which permits unrestricted use, distribution, and reproduction in any medium, provided you give appropriate credit to the original author(s) and the source, provide a link to the Creative Commons license, and indicate if changes were made.

\section{References}

1. Hou BX, Meng Zhang L, Guo J S., H. and Li J (2015) Development of a sensitive and specific multiplex PCR method for the simultaneous detection of chicken, duck and goose DNA in meat products. Meat Sci 101:90-94. https://doi.org/10.1016/j.meats ci.2014.11.007

2. Pegels N, Gonzalez I, Lopez-Calleja I, Fernandez S, Garcia T, Martin R (2012) Evaluation of a TaqMan real-time PCR assay for detection of chicken, turkey, duck, and goose material in highly processed industrial feed samples. Poult Sci 91(7):1709-1719. https://doi.org/10.3382/ps.2011-01954

3. Ren Y, Li X, Liu Y, Yang L, Cai Y, Quan S, Pan L (2017) A novel quantitative real-time PCR method for identification and quantification of mammalian and poultry species in foods. Food Control $76: 42-51$

4. Abe H, Hayano A, Inoue-Murayama M (2012) Forensic species identification of large macaws using DNA barcodes and 
microsatellite profiles. Mol Biol Rep 39:693-699. https://doi. org/10.1007/s11033-011-0787-1

5. Iyengar A (2014) Forensic DNA analysis for animal protection and biodiversity conservation: a review. J Nat Conserv 22:195-205. https://doi.org/10.1016/j.jnc.2013.12.001

6. Boonseub S, Johnston G, Linacre A (2012) Identification of protected avian species using a single feather barb. J Forensic Sci 57:1574-1577. https://doi.org/10.1111/j.1556-4029.2012.02206 . $\mathrm{X}$

7. Yalçınkaya B, Yumbul E, Mozioğlu E, Akgoz M (2017) Comparison of DNA extraction methods for meat analysis. Food Chem 221:1253-1257. https://doi.org/10.1016/j.foodchem.2016.11.032

8. Hogan FE, Cooke R, Burridge C, Norman J (2008) Optimizing the use of shed feathers for genetic analysis. Mol Ecol Notes 8(3):561-567. https://doi.org/10.1111/j.1471-8286.2007.02044.x

9. Rawlence NJ, Wood JR, Armstrong KN, Cooper A (2009) DNA content and distribution in ancient feathers and potential to reconstruct the plumage of extinct avian taxa. Proc R Soc Lond Ser B Biol Sci 276(1672):3395-3402. https://doi.org/10.1098/ rspb.2009.0755

10. Hird H, Chisholm J, Brown J (2005) The detection of commercial duck species in food using a single probe-multiple species-specific primer real-time PCR assay. J Eur Food Res Technol 221(34):559-563. https://doi.org/10.1007/s00217-005-1197-1

11. LeBlanc NM, Stewart DT, Pálsson S, Elderkin MF, Mittelhauser G, Mockford S, M. and Mallory L (2017) Population structure of Purple Sandpipers (Calidris maritima) as revealed by mitochondrial DNA and microsatellites. Ecol Evol 7(9):3225-3242. https ://doi.org/10.1002/ece3.2927

12. Speller C, Nicholas G, Dongya Y (2011) Feather barbs as a good source of mtDNA for bird species identification in forensic wildlife investigations. Investig Genet 2:16. https://doi. org/10.1186/2041-2223-2-16 